\title{
La influencia de la iconografía soviética en el imaginario colectivo de la izquierda española de los años 30
}

\author{
INMACULADA COLOMINA LIMONERO \\ Doctora en Historia Contemporánea. UNED \\ The influence of soviet iconography of the spanish left \\ in the 1930's
}

\begin{abstract}
RESUMEN
En la presente exposición vamos a conocer no solamente cual fue la imagen de la Unión Soviética en la España de la década de 1930, sino que también prestaremos especial atención al «otro lado» pues conoceremos la imagen que proyectaba España en la Unión Soviética durante la misma época. Combinando la investigación histórica y diversos materiales de archivo extraídos de la antigua Unión Soviética, se analiza el impacto causado sobre algunos sectores de la izquierda española de películas soviéticas que gozaron de éxito en esos años.

\author{
PALABRAS CLAVE \\ España años 30, guerra civil, películas \\ soviéticas, imagen URSS en España, \\ españoles en la Unión Soviética, Dolores \\ Ibarruri.
}

\begin{abstract}
This article not only analyses the image of the Soviet Union held in Spain during the 1930s, but also pays special attention to the image held of Spain at the "other side", that is, the Soviet Union, during the same period.

Combining historical research based on the examination of a diversity of materials from files extracted from different sources, including the archives of the former Soviet Union, the article analyses the impact and popularity of soviet films amongst some sectors of the Spanish left.
\end{abstract}

\section{KEY WORDS}

Spain 1930s, civil war, Soviet films, images and perceptions of USSR and Spain, Spaniards in the Soviet Union, Dolores Ibarruri. 


\section{INTRODUCCIÓN HISTÓRICA}

Situadas a uno y otro extremo del continente europeo, Rusia y España distantes entre sí, históricamente se han dispensado mutua simpatía.

Desde el siglo XV existen documentos que prueban la presencia de algunos viajeros rusos en España. En el siglo XVI, comenzaron las relaciones comerciales entre ambos países, creándose en 1525 la primera embajada moscovita en la España de Carlos V. Tiempo más tarde en 1740 se firmó un tratado comercial, lo que llevó a que, en 1771, se creara la primera oficina comercial española en San Petersburgo.

En el siglo XIX se llevaron a cabo numerosos contactos e intercambios culturales entre los dos países que en el siglo XX se acrecentaron, en especial tras la revolución rusa de 1917 y también durante el periodo de la II Republica.

Pese a todo, el desconocimiento entre las dos partes continuaba siendo notable. Si bien es cierto que hubo viajeros e intelectuales de izquierdas españoles que tuvieron información de primera mano ${ }^{1}$ y siempre mantuvieron lazos con la Unión Soviética y que además intentaron difundir su cultura en nuestro país.

En abril de 1934 se creó la Asociación de Amigos de la Unión Soviética, entidad que trataba de fomentar el acercamiento cultural e intelectual entre los dos países. Fue fundada por un grupo de intelectuales españoles con el fin de dar a conocer a la URSS en España y para ello llevaron a cabo numerosas actividades.

Entre los firmantes de la configuración de esta entidad destacaban personajes tan ilustres de la cultura española como Pío Baroja, Victoria Kent, Gregorio Marañon, Jacinto Benavente, Vallé Inclán, etc².

Un año antes, en julio de 1933 se procedió al establecimiento de relaciones entre España y la Unión Soviética pero, por causas fortuitas no se llegaron a intercambiar embajadores.

Los cambios gubernamentales en la década de 1930, no permitieron la reanudación de las relaciones oficiales hasta un mes después de iniciada la guerra civil ${ }^{3}$. La Unión Soviética tuvo representación diplomática a partir de julio de 1936 y en septiembre se creó la Embajada de la República Española en Moscú. De modo que, a finales de 1936, las relaciones entre los dos países fueron muy fluidas.

1 «Rusia fue visitada por españoles no sólo simpatizantes comunistas sino también periodistas o invitados oficiales del gobierno e incluso simples curiosos. Algunos de estos viajeros obtuvieron con sus crónicas y libros gran resonancia». En AVILÉS FARRÉ, J. La fe que vino de Rusia. La Revolución bolchevique y los españoles (1917-1931). Madrid, Biblioteca Nueva, 1999, pp. 283-284.

2 Sobre las Asociaciones de Amigos de la Unión Soviética véase Tesis Doctoral de Maria Magdalena Garrido Caballero: Las relaciones entre España y la Unión Soviética a través de las Asociaciones de Amistad en el siglo XX. Universidad de Murcia, año 2006.

3 Véase: CASANOVA, M.: La Diplomacia española durante la Guerra Civil. Madrid, Biblioteca Diplomática Española, Sección Estudios. Ministerio de Asuntos Exteriores, 1996, p. 67. 


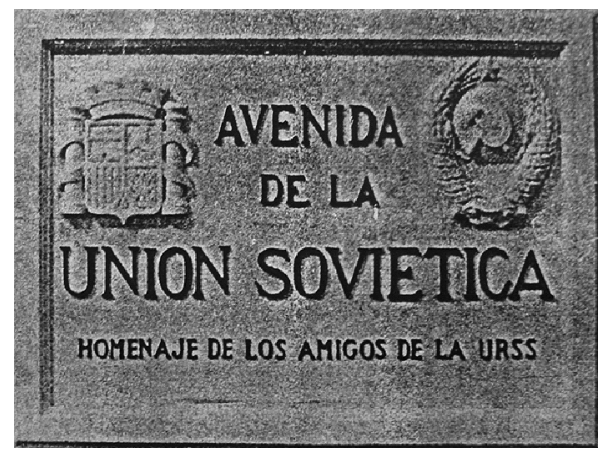

Valencia. Antigua calle Conde de Peñalver.
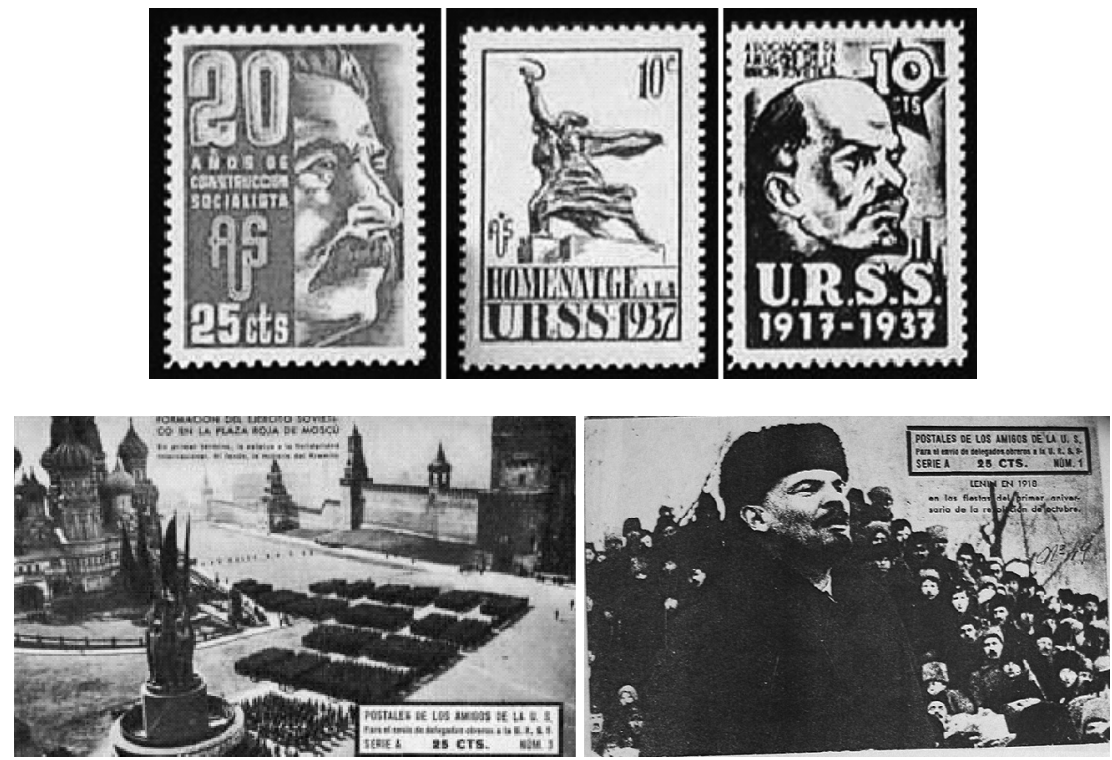

Sellos y postales con clara referencia a la Unión Soviética editados por la Asociación Amigos de la URSS.

La Unión Soviética se caracterizó por su pronta movilización social a favor de la causa republicana. En los primeros meses de la guerra y bajo un gran entusiasmo, pues la contienda se vivió con mucha intensidad, el pueblo soviético, en una reacción espontánea, decidió ayudar económicamente al gobierno republicano español. Esta fue la primera ayuda que se recibió desde el extranjero. 
Se realizaron recolectas en las fábricas o distintos lugares de trabajo de todo el país y se envió ayuda monetaria ${ }^{4}$. Por iniciativa de las obreras de Manufacturas Triojgornai (Tres Montañas) de Moscú, se recogieron 47 millones de rublos de la época para ayudar a la República española ${ }^{5}$ y la fábrica textil Dzerzhinski envió a España artículos de primera necesidad que salieron del puerto de Odessa el 18 de septiembre de 1936. Por su parte, los empleados de las fábricas de motores Stalin y Kaganovich entregaron una cuarta parte del sueldo de una jornada a favor de los niños y de las mujeres españoles. En todo momento, estas ayudas fueron apoyadas o promovidas por el gobierno de la Unión Soviética sobre las cuales ejercía un control absoluto ${ }^{6}$.

En los años 30, la Unión Soviética entre algunos sectores de la izquierda española gozaba de una imagen ideal, aunque no exenta de matices ideológicos. Se la consideraba como un país amigo y el paradigma del socialismo.

Tenía un efecto bipolar. Considerada por algunos bajo el calificativo de infierno, o por otros de paraíso obrero, constituyó el máximo referente simbólico de algunos sectores de la izquierda española ${ }^{7}$, y para las derechas supuso el llamado temor bolchevique o el peligro rojo ${ }^{8}$.

Éstas veían a la URSS como el gran enemigo, con siniestras intenciones, por los que eran dos visiones sustancialmente distintas. Lo cierto es que las miradas solían ser a través de un prisma muy particular que impedían tener una imagen certera.

Para los comunistas, era el país revolucionario por excelencia. Se sentían fascinados por su modelo de Estado, constituía el gran ideal, la patria del proletariado. El espejo y el modelo a seguir.

Y a ojos de la gran mayoría de la población española, la Unión Soviética era una fría y lejana tierra incógnita.

${ }^{4}$ En PONS, E.: Las guerras de los niños republicanos. Madrid, Compañía Literaria, 1997, p. 696.

5 En CASANOVA, M.: Op. cit., p. 68.

6 Ibidem. p. 67.

7 «La mera abundancia de publicaciones sobre Rusia fueran favorables o contrarias, era una prueba del genuino interés publico por la experiencia soviética.» En AVILÉS FARRÉ, J.; Op. cit., 1999, p. 314. Haciendo referencia a los inicios de la década de 1930. Sobre este aspecto el autor menciona que "Según un artículo del diario ABC en enero de 1931, se muestra la preocupación por la gran cantidad de libros favorables a la URSS que se estaban publicando en España.» p. 316.

8 Sobre el temor a un posible "contagio» ver obra de J. AVILÉS FARRÉ citada 1999, pp. 91.95. 

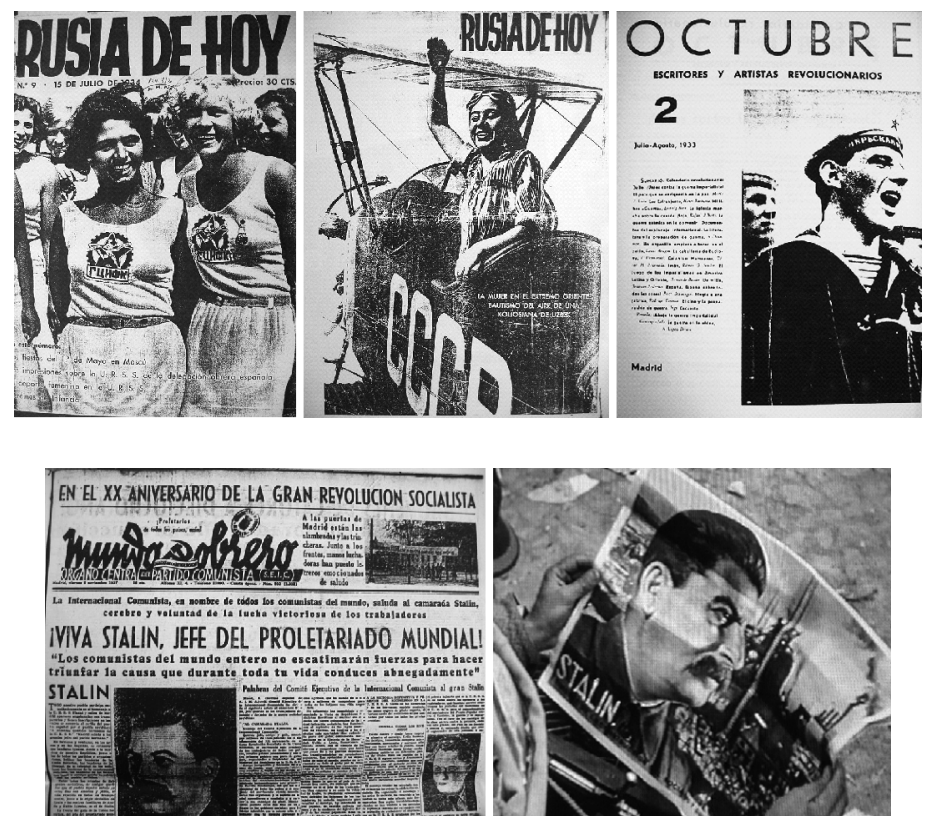

Prensa española de los años 30.
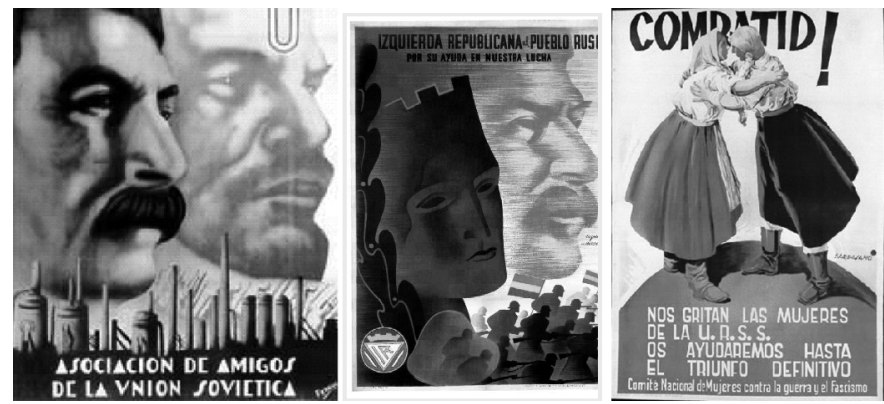

Muestra de cartelismo de inspiración soviética.

\section{LA IMAGEN DE ESPAÑA EN «EL OTRO LADO»}

En la Unión Soviética la imagen que se tenía de España y de los españoles estaba llena de estereotipos. La literatura soviética estuvo impregnada de los tópicos sobre su cálido clima, paisaje exótico y apasionado carácter latino, cargado de hondas tradiciones. 

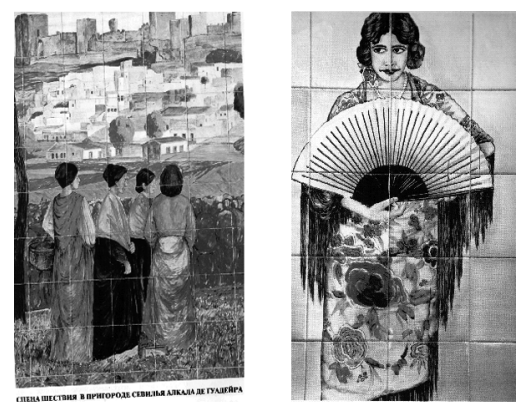

Imágenes de España, años 30. Archivos soviéticos.

En la imaginación popular de los soviéticos, España era un país bravo azotado por una guerra provocada por un alzamiento militar fascista. Esta corriente de simpatía por «todo lo español» provocó un auge del interés por el idioma y una reacción de las editoriales que se afanaron en publicar novelas sobre España, traducciones de literatura y poesía española así como estudios de Historia peninsulares. En abril de 1938 se inauguró en la mayor biblioteca del país, la Biblioteca Lenin una sección española con materiales importados de la España republicana.

El pueblo soviético conocía y cantaba las canciones españolas. A finales de los años treinta se editaron cuadernos recopilatorios de cantos folklóricos traducidos al ruso ${ }^{9}$. Algunos títulos fueron: «Pasaremos», «Canciones antifascistas», "Canciones populares catalanas» $\mathrm{y}$ «Cantamos».

También hubo composiciones musicales y teatrales. A modo de ejemplo, hubo una obra de teatro de éxito del autor A. N. Afinogenov llamada Salut Ispania! En ella se relataba la suerte que corrían en la guerra civil un grupo de voluntarios comunistas y en la que la actriz principal, Ksenia Sukovskai, interpretaba el papel de Dolores Ibárruri.

Inspirados en España, fueron muy populares en tierras soviéticas los lemas atribuidos a Dolores Ibárruri: «No pasaran ${ }^{10} 0$ «Es mejor morir de pie que vivir de rodillas». Inspirándose en esta consigna, el escritor y corresponsal soviético llya Ehrenburg compuso en 1937 su obra «Vne peremiria» de gran éxito en la URSS.

Por otro lado, según palabras del autor ruso Yuri Rybalkin ${ }^{11}$, la guerra civil española influyó también - y en este caso fue para mal—en referencia a las terribles purgas soviéticas que se llevaron a cabo durante los años 30.

9 ANC. Fondo 555. carp 65.

10 La dirigente comunista pronunció estas palabras durante un discurso ante los micrófonos del Ministerio de Gobernación de la República española el 19 de julio de 1936, como respuesta a la sublevación militar.

11 RYBALKIN, Y.: Stalin y España. Madrid, Marcial Pons, 2007, p. 32. 
«En la URSS se empezó a usar la locución «Quinta Columna"12», nacida en la guerra civil española para aludir a supuestos espías y saboteadores al servicio del enemigo.

Y buena parte de la represión en la Unión Soviética se llevó a cabo bajo la advocación de combatir a la Quinta Columna».

Entre la población soviética, la situación bélica de España fue tema de conversación muy común y estuvo presente en todos los medios de comunicación soviéticos, pues la gran mayoría enviaron a sus corresponsales a cubrir la noticia sobre el terreno de batalla, por lo que el pueblo dispuso de varias fuentes de información sobre los acontecimientos que se vivieron durante la contienda ${ }^{13}$.

La editorial del Partido Comunista soviético editó un folleto explicativo bajo el titulo «España Heroica», dirigido a las células propagandistas del Partido, con el objetivo de informar a los colectivos obreros sobre la situación bélica española en las reuniones que tenían lugar en los centros de trabajo.

En las salas de cine soviéticas era costumbre antes del inicio de las películas ofrecer un pequeño documental informativo (tipo NODO) y durante los años de la guerra civil, este espacio estuvo en muchas ocasiones dedicado a lo que sucedía en España ${ }^{14}$.

Todos estos aspectos mencionados, llevaron a que crecieran los lazos de amistad y que la vinculación entre los dos países se estrechara.
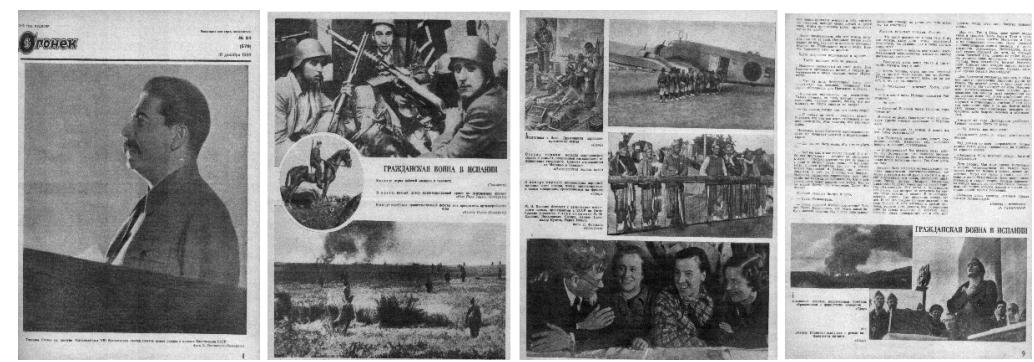

Prensa soviética. Noticias sobre la guerra en España, 10 diciembre 1936.

\footnotetext{
12 La expresión «Quinta columna» se atribuye al general Mola, quien al referirse en 1936 al avance de las tropas sublevadas en la guerra civil española hacia Madrid dijo que cuatro columnas se dirigían hacía el norte y había una quinta formada por los militantes que dentro de la capital trabajaban clandestinamente en pro de la victoria franquista.

13 NOVIKOVA, O.: «Las visiones de España en la Unión Soviética». En Historia del Presente. Miradas sobre España. n¹1, 2008, p. 18.

14 Ibidem, p. 18.
} 


\section{LA AYUDA PRESTADA}

La intervención extranjera en la guerra civil española es un tema controvertido y es indudable que el apoyo soviético tuvo consecuencias fundamentales en la historia del conflicto.El gesto solidario hacia España constituía para el régimen stalinista una sutil maniobra de distracción y propaganda. Distraía la atención del terror masivo ${ }^{15}$ sufrido en la Unión Soviética durante el período de 1932 a 1939, uno de los más sangrientos.

El día 14 de septiembre de 1936 comenzó de forma oficial la conocida «Operación $X$ », que llevó a España numerosos recursos humanos y materiales procedentes de la Unión Soviética. Con esta ayuda, Moscú pretendía disponer en la República española victoriosa de un aliado en la zona del Mediterráneo occidental. Por este motivo, no se puede considerar la ayuda soviética como altruista.

La movilización y empleo de las reservas metálicas de oro y plata del Banco de España fueron indispensables para la financiación exterior de la guerra civil española ${ }^{16}$. La utilización de este oro fue objeto de duras críticas por parte del bando fascista, que se encargó de difundir el mito del despilfarro de las reservas monetarias del país. Pero lo cierto es que resultó vital para obtener armas y material para la defensa y hacer frente a la sublevación rebelde.

Según el autor Pablo Martín Aceña en su libro El oro de Moscú y el oro de Berlín, afirma:

«Es indiscutible que el gobierno soviético ayudó a la República española si bien hay que destacar que lo cobraron todo: los fletes, montajes, armamento, reparaciones y el material así como todos los gastos de los asesores políticos y militares soviéticos acuartelados en España, y los cursillos que se impartían de adiestramiento para los jóvenes pilotos españoles en territorio soviético ${ }^{17}$ ».

Un ejemplo de la ayuda prestada lo aporta un documento extraído de los archivos soviéticos ${ }^{18}$ con fecha de agosto de 1938 remitido por el responsable de la Cruz Roja Soviética y dirigido a Stalin, se solicitan entre otros víveres destinados a España:

Verduras . -25.000 toneladas, Pescado congelado. -7.500 toneladas

Carne en conserva. -3.000 toneladas, Carne congelada. -7.000 toneladas

Carne de cerdo. -500 toneladas, Conservas. -700 toneladas

Leche condensada. - 200.000 unidades, Queso._- 200 toneladas

15 Véase entre otros, el texto de Antonio Fernández García «Sobre el terror estalinista: la documentación desclasificada». En Cuadernos de Historia Contemporánea, vol. 24, 2002, pp. 301-315.

16 VIÑAS, A.: El oro español en la Guerra Civil. Madrid, Instituto Estudios Fiscales, 1976.

17 MARTÍN ACEÑA, P.: El oro de Moscú y el oro de Berlín. Madrid, Taurus, 2001, p.127.

18 Archivo CRAI-UB. F. AM. AM4-12/a. 
Azucar . - 13.000 toneladas, Huevos. -20.000 unidades

Café. -1.000 toneladas, Cacao.-750 toneladas

Con referencia a los efectivos humanos, desde la URSS llegaron a España numerosos asesores militare ${ }^{19}$ y se nutrió de consejeros soviéticos al gobierno republicano. El asesoramiento tuvo lugar en muchos ámbitos: marina, artillería, radio y comunicación, etc., pero muy especialmente tuvo lugar en el ámbito de la aviación ${ }^{20}$.

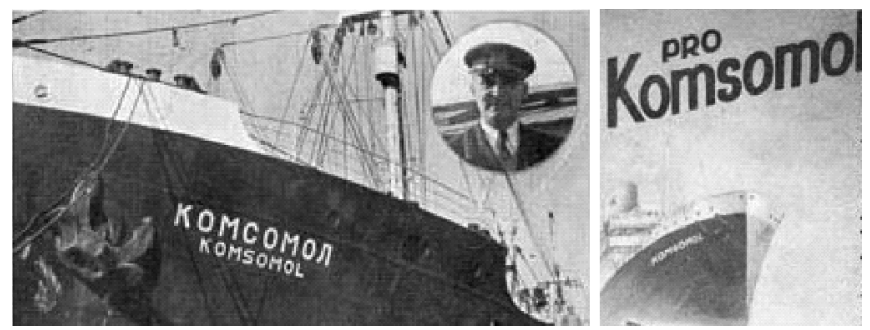

Barco Komsomol. Icono de la ayuda soviética a España, 1937.

Se estima que fueron 1.955 los militares soviéticos que viajaron a España a apoyar la República. (aviadores, tanquistas, mecánicos, logístas, instructores, etc. $)^{21}$

Todos ellos, participaron en el adiestramiento y la dirección del nuevo Ejército Popular y milicias de la República española. Su influencia fue patente en estas organizaciones puesto que adoptaron como insignias la Estrella Roja y el saludo con el puño en alto.

\section{LAS PELÍCULAS SOVIÉTICAS}

Existió una estrecha relación entre cultura y propaganda como medio de difusión de gran impacto entre las masas. Durante la dura batalla que tuvo lugar por la defensa de la capital española, por todas partes era posible observar carteles con el lema inspirado en la Revolución Rusa «Hay que defender a Madrid como a Petrogrado».

19 Según datos extraídos de los archivos soviéticos, se estima en unos 600 asesores. En RYBALKIN, Y.: «Sobre la cuestión de la ayuda militar soviética a la España republicana (1936-1939)», Moscú, Actas de la Il conferencia de hispanistas de Rusia, 1999, pp. 242-246.

20 Como ejemplo sirvan los nombres «españolizados» de algunos jefes de escuadrilla soviéticos llegados a España para asesorar en temas militares: Pavel Vassiliev Richagov que, debido a la dificultad de pronunciar su nombre era conocido por los españoles con el sobrenombre de -Pablo Palancar-o, el también aviador Ivan Kopets al que llamaban simplemente - Antonio-.

21 Según ALQUEZAR, R.: «Brigadas Internacionals i ajut internacional». En Bonamusa, F.: Barcelona, Actes del II Seminari sobre la Guerra Civil i el Franquisme a Catalunya, 1997, p. 99. 
Dentro del contexto de proliferación de lemas impactantes dirigidos a las masas, las películas soviéticas jugaron un importante papel dado que poseían mensajes aleccionadores contra el enemigo burgués e incitaban a la lucha. Su propósito era educador y seguían una línea perfectamente definida.

El cine soviético de los años 30 se sitúa dentro de la corriente del realismo socialista que caracterizó la época ${ }^{22}$. En él se ensalzaba a los trabajadores y a la revolución. Ayudaba a la clase obrera a educarla en el espíritu del socialismo, a elevar su nivel de cultura y su capacidad de lucha política. Legitimaban la revolución y animaban a los luchadores antifascistas de todo el mundo a implantarla en sus respectivos países.

Durante la década de 1930, en España, diversas películas de la Unión soviética impactaron y enervaron los sentimientos revolucionarios entre las izquierdas. Llegaron grandes producciones que fueron exportadas con claros objetivos de difusión del modelo del ideal Estado soviético. Fueron muy promocionadas, la publicidad de las películas no se encontraba sólo en los periódicos sino también en las calles, en las paredes y farolas. Contaron un público minoritario, aunque muy entusiasta y los héroes soviéticos se hicieron muy populares entre las masas de trabajadores y milicianos españoles.

Donde tuvieron mucho campo fue en el frente, dado que se producía un efecto de clara identificación entre los soldados republicanos y los de las películas que animaban a continuar la lucha. Los combatientes de las películas soviéticas no tenían dudas, no tenían miedos y su determinación era ilimitada. Todo ello visto en el frente de guerra, suponía una gran inyección de moral para las tropas republicanas y también en la retaguardia.

El culto a la personalidad llevó al cine soviético a crear protagonistas ideales, verdaderos maestros y directores de masas, cuya conducta se convirtió en ejemplo a imitar. Esta exaltación del héroe estaba muy relacionada, por un lado, con el aspecto educador de la propaganda soviética, es decir, el héroe era además un maestro, un modelo de vida; y por otro, estaba el exacerbado culto a la personalidad, magnificada hasta el máximo.

Fruto de esta gran presión ideológica surgieron filmes, en su mayoría de gran calidad. Algunos títulos fueron proyectados en España durante la guerra civil: La línea general, Amor y Odio, La tierra, El circo, Las tres canciones de Lenin, Octubre, La juventud de Máximo, El carné del partido, etc.

22 El realismo socialista es una corriente estética cuyo propósito era llevar los ideales del comunismo al terreno del arte. Fue la tendencia artística predominante durante gran parte de la historia de la Unión Soviética, particularmente durante el gobierno de lósif Stalin, en la República Popular China y, en general, en la mayoría de países socialistas. El director de cine Serguéi Eisenstein fue la figura más representativa del realismo socialista del cine soviético. 


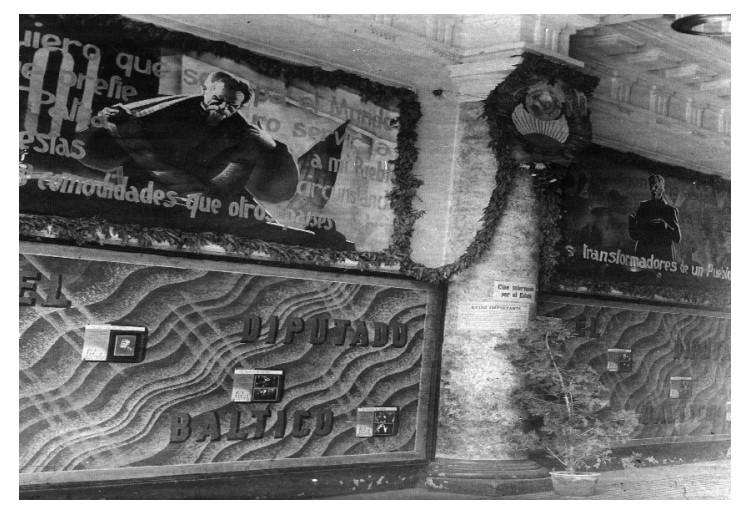

Pared Mural de Valencia con imagen de Troski y propaganda de la película Los Marinos del Báltico. Año 1937.

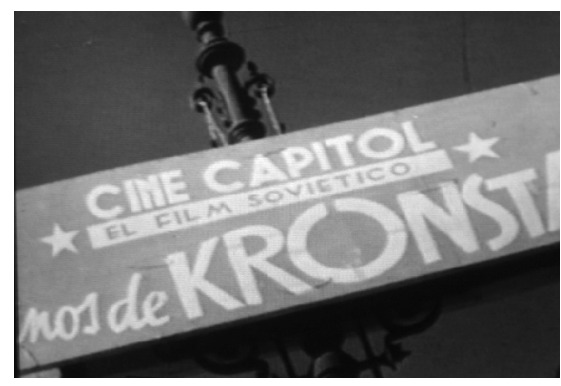

Pared Mural de Valencia con imagen de Troski y propaganda de la película Los Marinos del Báltico. Año 1937.

Todas ellas llegaron a España junto a otros materiales con las Brigadas Internacionales y a través de las Asociaciones de Amistad o algunas productoras de cine como Laya Films de Barcelona ${ }^{23}$.

Las cintas más distribuidas durante la guerra y que recrearon de forma gloriosa a sus héroes protagonistas fueron "Acorazado Potemkin» de 1925, "Octubre» de 1927, "Tchapaev»"24 de 1934 y «Los marineros de Krondstadt» de 1936.

Acorazado Potiemkin es una película parcialmente basada en hechos reales, que acontecieron en el puerto de Odessa (Ucrania) durante la semana de 26 de ju-

23 La productora Laya Films formó parte del Organismo de Propaganda de la Generalitat de Catalunya y se dedicó, básicamente, al reportaje sobre la guerra, tanto en el frente como en la retaguardia. Su objetivo fue que el conflicto se conociera por todo el mundo.

24 Durante la Guerra Civil española, existió en el ejército republicano un batallón que tomó su nombre. 


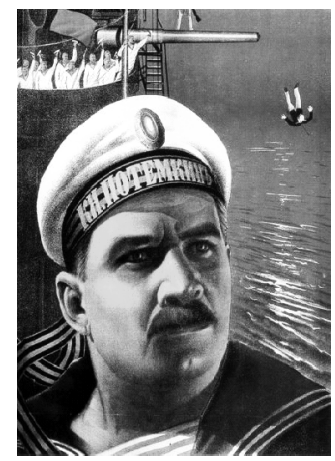

Cartel propagandistico de la película El Acorazado Potiemkin.

nio de $1905^{25}$. Refleja el espíritu de la época en que es realizada, donde todo elemento es utilizado para la legitimación ideológica de una revolución por aquel entonces naciente. Llena de imágenes expresivas, se presenta como un álbum fotográfico y representa la magnificación por la figura de las masas y las causas colectivas.

Resaltaba la importancia que tuvieron los marineros en el proceso de la revolución fallida de 1905, —antecedente de la rebelión de octubre de 1917- El cambio constante en la acción, genera en el espectador una emoción, -un shock-, que le inducen a realizar mediante un proceso psicológico, una reflexión intelectual sobre lo que esta ocurriendo.

La película Tchapaev fue creada en 1934 y en España se presentó con el nombre «Tchapáev, el guerrillero rojo». Aportaba la solución soviética que había llevado consigo la formación del glorioso Ejército Rojo, que la propaganda se encargaba de exaltar como uno de los factores clave de la construcción del socialismo. Muestra un ejemplo de cómo la organización y la estructura jerárquica del ejército resultaba fundamental para ganar las batallas. El argumento se basa en las hazañas en el ejército regular de un audaz guerrillero que pasó a trabajar bajo la tutela de un comisario político del Partido Comunista.

Fue concebida desde la óptica del realismo socialista y se sitúa dentro de la concepción del culto a la personalidad. Tchapáev fue el primer gran héroe cinematográfico individual del realismo socialista. La figura del guerrillero, la Guerra Civil Rusa, el papel del comisario político, la integración en tropas regulares... Todos estos temas estaban presentes como problemas de primer orden en la guerra de España.

${ }^{25}$ La película fue prohibida en Alemania durante el régimen Nazi, Gran Bretaña, España (aunque se levantó la prohibición durante la Segunda República), Francia y otros países por su contenido revolucionario. 

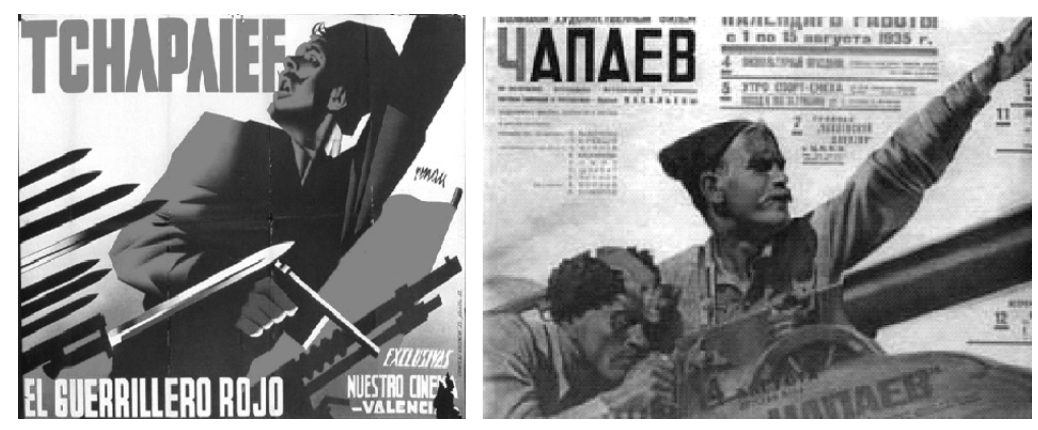

Carteles de promocion de la película Tchapaev.

Por regla general, las películas solían ir precedidas de una explicación acerca de las conclusiones que debían ser extraídas de los filmes eminentemente pedagógicos. Sobre esta película, el corresponsal soviético en España llya Ehrenburg, famoso por sus artículos llenos de pasión antifascista, explica en sus «Crónicas sobre España» enviadas al diario Izvestia en 1936:

«Nosotros montábamos sesiones de cine tanto en las plazas donde una simple pared blanca ya nos servía de pantalla, como en una iglesia que, por milagro estuviera intacta, como en los comedores...

Después de la primera tarde de sesión de Tchapaev, decidimos quitar el final de la película: los combatientes españoles jóvenes no podían aceptar su muerte. Decían: ¿Para qué vamos a combatir si los mejores mueren?

A veces, interrumpían la película exclamaciones como: ¡Viva Tchapáev! Recuerdo que una vez un anarquista gritó: ¡Muera el comisario!; y todos los demas aplaudieron. (...)

A menudo, después de la sesión, se acercaban a mí y daban las gracias al comisario ruso que prohibía la requisa de cerdos, y me pedían que yo le escribiera a él, sobre los desórdenes que había en el pueblo español. Para ellos, la película era un noticiario real y estaban convencidos que tanto Tchapáev como Furmánov vivían aún en Moscú².

También, como apoyo moral a la República y junto a las películas, la Unión Soviética envió a España libros, carteles, periódicos y música. Por su parte, España mandó a la URSS una muestra de su cultura y literatura y como embajadores culturales a artistas, deportistas, literatos...

A semejanza con el cine, hubo canciones soviéticas muy sonadas entre los luchadores antifascistas españoles cuyas letras poseían gran carga de retórica revolucionaria, siempre a favor de la lucha por la libertad y contra el fascismo.

${ }^{26}$ EHRENBURG, I. (1986). Gentes, años, vida. Barcelona, Planeta, 2003. 
Algunos títulos de canciones soviéticas famosas en España fueron: «La marcha de Budionny 27" «Nuestra locomotora» «Somos los forjadores» «Al combate iremos» "Canto de los supervivientes» «Elegía a los mártires» «El fusilamiento de los comuneros» «La joven guardia» O «La Bandera Roja».

\section{LA INFLUENCIA DE LA UNIÓN SOVIÉTICA EN OTROS ÁMBITOS DE LA VIDA CULTURAL ESPAÑOLA}

En el periodo de la II República, la cultura dejó de ser para la elite y pasó a estar al servicio del ciudadano: Las ciudades dispusieron de un nuevo urbanismo racionalista, obras arquitectónicas, más bibliotecas y museos, escuelas populares, viviendas, centros de estudio, ateneos, círculos artísticos, asociaciones culturales y deportivas, teatros y cines....Todo bajo el impulso y la vanguardia revolucionaria.

La difusión, la defensa de la cultura dirigida al pueblo y la promoción de la educación, fueron objetivos prioritarios durante el periodo y muchas acciones educativas tuvieron como referencia el sistema educativo soviético.

Durante los años 30 en diversas ciudades de España, se representaron obras de teatro con temas de inspiración soviéticos. Algunos títulos famosos fueron: Nuestra Natacha, La tragedia optimista y la zarzuela Katiuska.

En Madrid, en 1938, tuvo lugar una exposición fotográfica a través del patrocinio del VOKS, (Sociedad para las Relaciones Culturales de la URSS con el extranjero) bajo el título: «Exposición fotográfica soviética». En ella se mostraban fotos del país hermano. Se trataba de un país idílico en el que absolutamente todos
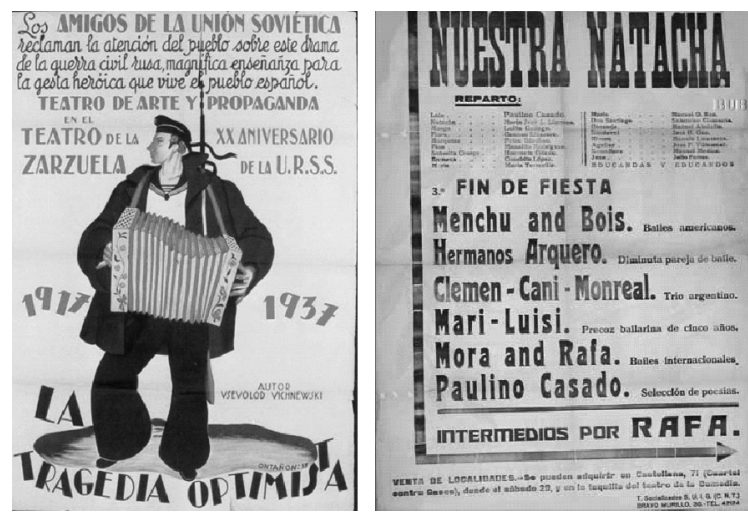

Publicidad de obras de teatro con clara inspiración soviética.

27 Budionny, Semion Mijailovich. Jefe militar bolchevique, (1883-1973) Gozó de gran popularidad y del favor de Stalin. Fue proclamado héroe de la URSS. 


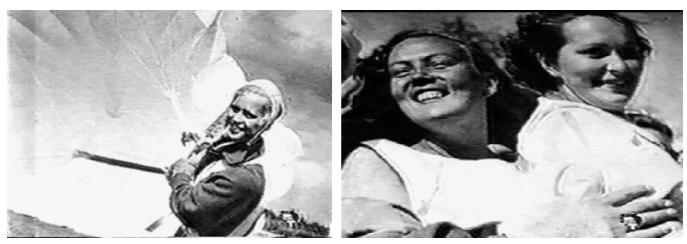

Exposición fotográfica soviética. Madrid, 1938.

los rostros fotografiados sonreían felices y dichosos por vivir en la Gran patria del socialismo. Aparecían niños de ojos azules y cabellos rubios ${ }^{28}$ con el pañuelo de pionero flotando al viento. Esta exposición fue visitada por muchos ciudadanos españoles y de igual modo numerosas escuelas de niños, quedando deslumbrados por la propaganda de la maravillosa vida soviética ${ }^{29}$.

Por todos los motivos anteriormente citados, la Unión Soviética con su imagen de país hermano, se convirtió en un destino considerado como privilegiado por los exiliados políticos que se vieron obligados a abandonar España en los últimos momentos de la Guerra Civil. Fue el lugar elegido para su exilio por los máximos dirigentes del Partido Comunista de España, Dolores Ibárruri, José Díaz y Jesús Hernández que, con su ejemplo arrastraron a otros cuadros políticos, organizativos y militares del Partido en su éxodo hacia el país de los trabajadores.

Aproximadamente, fueron unos mil trescientos cuadros militares y políticos acompañados de sus familias, la mayoría de ellos con clara vinculación al Partido Comunista español. A partir de entonces, el grupo de los españoles mayores, además de los tres mil niños llegados durante la guerra civil, constituyeron el colectivo más numeroso en la historia de la presencia española en Rusia.

\section{BIBLIOGRAFÍA Y FUENTES DE INFORMACIÓN}

ALTED VIGIL, A. NICOLÁS MARÍN, E. GONZÁLEZ MARTELL, R.: Los Niños de la guerra de España en la Unión Soviética de la evacuación al retorno 1937-1999. Madrid, Fundación Largo Caballero, 1999.

ALTED VIGIL, A.: «Los exilios de la España contemporánea». Revista Ayer, Madrid, año 2002. pp.129154.

- «La voz de los vencidos». Madrid, Aguilar, 2005.

ARASA, D.: Los españoles de Stalin. Barcelona, Belacqua, 2005.

AVILÉS FARRÉ, J.: La fe que vino de Rusia. La Revolución bolchevique y los españoles (1917-1931). Madrid, Biblioteca Nueva, 1999.

- Las grandes potencias ante la guerra de España. Madrid, Arco Libros, 1998.

BONAMUSA, F.: Seminaris sobre la Guerra Civil i el Franquisme a Catalunya. Ajuntament Barberà del Vallès, años 1996-2000. «Barcelona and the Internationals Brigades. Memory to the Homage, 1978-

28 Paradigmas de la inocencia y la pureza.

29 Información extraída del documental de la serie de televisión de A. ARLAUSKAS: Vivir y Morir en Rusia. cap.V. Año 1994. 
2000» Xavier Bosch (ed.): Archie Cochrane: Back to the Front. Barcelona, Cochraine Fondation. 2003, pp. 296-305.

CASANOVA, M.: La Diplomacia española durante la Guerra Civil. Madrid, Ministerio de Asuntos Exteriores. Biblioteca Diplomática española, 1996.

COLOMINA LIMONERO, I.: «Los niños de la guerra de España en la Unión Soviética». En Actas del III Congreso sobre El Republicanismo. Priego de Córdoba, 2005, pp. 395-413.

- «El Rusiñol. Aspectos culturales y linguísticos del exilio español en la Unión Soviética». En Actas Congreso sobre la Guerra Civil española, Madrid, noviembre de 2006.

EGIDO LEON, M.A.: «Del paraíso soviético al peligro marxista: La Unión Soviética en la España republicana (1931-1936)». Cuadernos de historia contemporánea, n 10, 1988.

EHRENBURG, I.: Gentes, años, vida. Barcelona, Planeta, 2003.

EIROA, M.: Las relaciones de Franco con la Europa Centro- Oriental (1939-1955). Barcelona, Ariel, 2001.

ELORZA, A. BIZCARRONDO, M.: Queridos camaradas. La Internacional Comunista y España 19191939. Barcelona, Planeta, 1999.

ELPATIEVSKI, A.V.: Ispanskaia Emigratzia b CCCP. (La emigración española en la URSS), Moscú, Ed. Tver, 2002.

- «Ispanskaia Emigratzia b CCCP.» Revista Novi Mir, n 4. Moscú, año 2003.

FERNÁNDEZ GARCÍA, A.: «Sobre el terror estalinista: la documentación desclasificada». En Cuadernos de Historia Contemporánea, vol. 24 , 2002, pp. 301-315.

FERRO, M.: Historia Contemporánea y cine. Barcelona, Ariel, 1995.

GARRIDO CABALLERO, M.: Las relaciones entre España y la Unión Soviética a través de las Asociaciones de Amistad en el siglo XX. Universidad de Murcia, 2006.

KOWALSKY, D.: La Unión Soviética y la Guerra Civil española. Barcelona, Crítica, 2003.

MARTIN ACEÑA, P.: El oro de Moscú y el oro de Berlín. Madrid, Taurus, 2001

NOVIKOVA, O.: «Las visiones de España en la Unión Soviética». En Historia del Presente. Miradas sobre España. n० 11, 2008.

ADOSH, M. HABECK, R. SEVOSTIANOV,G.: España traicionada. Stalin y la Guerra Civil. Barcelona, Planeta, 2002. pp. 60-67, doc.11-13.

RYBALKIN, Y.: «Sobre la cuestión de la ayuda militar soviética a la España republicana (1936-1939). Actas de la ll conferencia de hispanistas de Rusia, Moscú, 1999, pp. 242-246.

- Stalin y España. Madrid, Marcial Pons, 2007.

Ríos de los, F.: Mi viaje a la Rusia sovietista. Madrid, Alianza, 1970.

ROSENSTONE, R.A.: El pasado en imágenes. El desafío del cine a nuestra idea de la historia. BarceIona, Ariel, 1997.

SANZ GUITIÁN, P.: Viajeros españoles en Rusia. Madrid, Compañía Literaria, 1995.

VIÑAS, A.: El oro de Moscú y el oro de Berlín. Madrid, Taurus, 2001.

- La soledad de la República. Barcelona, Crítica, 2007.

- El escudo de la república. Barcelona, Crítica, 2007.

\section{DOCUMENTOS AUDIOVISUALES}

ARLAUSKAS, A.: Vivir y morir en Rusia. Serie de televisión de nueve capítulos. Director: Martín Ibarbia, Orio Produkzioak, Bilbao/Moscú. Años 1991 a 1994. 